\title{
EVANILDO BECHARA E A(S) MODERNA(S) GRAMÁTICA(S) PORTUGUESA(S): REFLEXÕES SOBRE A INSCRIÇÃO DO POLÍTICO NO IMAGINÁRIO DE LÍNGUA INSTITUIIDO NA/PELA GRAMÁTICA BRASILEIRA
}

\author{
THAÍS DE ARAUJO DA COSTA ${ }^{1}$
}

\author{
Programa de Pós-Graduação em Estudos de Linguagem \\ Instituto de Letras da UFF - Laboratório de Arquivos do Sujeito (LAS) \\ Rua Professor Marcos Waldemar de Freitas Reis, s/no. Campus do Gragoatá, Bloco C, \\ sala 518. CEP: 24210-201, Niterói - RJ \\ araujo_thais@yahoo.com.br
}

Resumo. Neste artigo, à luz da Análise de Discurso e da História das Ideias Linguísticas, propomo-nos a refletir acerca da inscrição do político, entendido como uma política de gestão das diferenças, no imaginário de língua que se impõe em duas gramáticas filiadas ao nome de autor do gramático brasileiro Evanildo Bechara, a saber: a $1^{a}$. e a $37^{a}$. edições da Moderna Gramática Portuguesa, publicadas em 1961 e em 1999, respectivamente. Para tanto, analisamos o prefácio e a introdução dessas obras. Em nossa análise, visamos, mais especificamente, compreender os efeitos produzidos no dizer do gramático sobre a língua (nomeada) portuguesa a partir da sua significação no século XX como patrimônio linguístico-cultural, buscando pensar ainda a relação estabelecida entre esse imaginário, a ilusão de unidade e homogeneidade linguística entre os povos ditos de língua portuguesa e o processo de colonização imposto por Portugal. Palavras-chave: discurso gramatical brasileiro; imaginário de língua; Moderna Gramática Portuguesa; Evanildo Bechara.

\begin{abstract}
In the present paper, we aim to discuss the inscription of the politic, understood as a differences management policy, in the imaginary of language that is imposed in two grammar books attached to the author's name of the Brazilian grammarian Evanildo Bechara, i.e. $1^{\text {st }}$ and $37^{\text {th }}$ editions of the Moderna Gramática Portuguesa, published in 1961 and 1999, respectively. This analysis is grounded in the Discourse Analysis in its relation to the History of Linguistic Ideas. To do so, we analysed the preface and the introduction of both works. In our analysis we aim, more specifically, to understand the effects produced in the grammarian's sayings towards the (socalled) Portuguese language since its signification, in the 20th century, as a
\end{abstract}

1 Doutora em Estudos da Linguagem pela Universidade Federal Fluminense. http://lattes.cnpq.br/9342507718155917. 
linguistic and cultural asset. We also eager to understand the relation stablished between this imaginary, the illusion of linguistic unity and homogeneity among the peoples designated as Portuguese speakers and the process of colonization imposed by Portugal.

Keywords: Brazilian gramatical discourse; Imaginary of language; Moderna Gramática Portuguesa; Evanildo Bechara.

\section{Introdução}

[...] a língua é uma maneira particular de fazer o liame social (...), o que faz que se possa dizer 'eles são eles, nós somos nós'.

Sériot (1993, p. 135).

A reflexão que ora apresentamos consiste num recorte de nossa tese de doutorado, na qual, sob o título Evanildo Bechara e a(s) Moderna(s) Gramática(s) Portuguesa(s): autoria, (re)produção, (re)formulação e circulação de sentidos sobre a língua no/do Brasil no século $X X I^{2}$, buscamos, a partir da articulação entre a Análise de Discurso (PÊCHEUX, [1975] 2009; ORLANDI, 2007c) e a História das Ideias Linguísticas (AUROUX, [1992] 2009; ORLANDI, 2009), compreender a relação entre função-autor gramático, imaginário de língua e forma de gramática ${ }^{3} \mathrm{em}$ dois instrumentos linguísticos ${ }^{4}$ distintos, a saber: a $1^{\text {a }}$. e a $37^{\text {a }}$. edições da Moderna Gramática Portuguesa, publicadas respectivamente em 1961 e em 1999. Neste artigo, tomando como objeto de análise os prefácios e as partes introdutórias dessas gramáticas, propomo-nos a refletir sobre a inscrição do político no imaginário de língua que nelas e por elas é instituído, passando a determinar não só a relação estabelecida entre as línguas em circulação em solo nacional, mas também entre os sujeitos que a elas se identificam para constituírem-se enquanto tais.

Como nos explica Orlandi (1998), o político é inerente às políticas linguísticas. Estas, segundo a autora, podem assumir formas mais explícitas - como, por exemplo, a instituição do Acordo Ortográfico da Língua Portuguesa assinado em 1990 e implementado oficialmente no Brasil em 1/1/2016, embora ainda siga em processo de implementação nos demais países signatários - ou menos evidentes - como a injunção à

\footnotetext{
${ }^{2}$ Tese desenvolvida sob a orientação da Profa. Dra. Vanise Gomes de Medeiros e defendida em maio/2016 na Universidade Federal Fluminense.

${ }^{3}$ Referimo-nos aqui à Orlandi (2002, p. 148) quando a autora afirma que "[...] a forma de gramática tem que ver com a forma de função-autor gramático e [...] isso tem consequências sobre o trabalho produzido pelo gramático na relação do sujeito com a língua, via representação [imaginária] dessa relação por instrumentos linguísticos".

${ }^{4}$ São instrumentos linguísticos, conforme Auroux (op. cit.), as gramáticas e os dicionários, no sentido em que estes, como objetos técnicos e empíricos investidos de conhecimentos teóricos explícitos, descrevem uma língua, ajudando-nos a falá-la e a lê-la. O autor chama-nos atenção ainda para a dimensão histórica desses instrumentos, nos quais comparecem saberes que se constituem (historicamente) num horizonte de retrospecção e de prospecção e para cuja compreensão faz-se, portanto, necessária a desnaturalização do processo de constituição do passado que os atravessa e os constitui (retrospecção) e a do futuro que deles se desdobra (prospecção).
} 
normatividade produzida na/pela gramática (DIAS, 2007). Em ambos os casos, no entanto, coloca-se em questão, tal como propôs Dias ${ }^{5}$, uma política de gestão das diferenças, isto é, dos diferentes modos de se dizer numa língua e, por conseguinte, de ter direito de nela assim dizer.

Articulada à reflexão tecida por Dias - porém antes dele -, Orlandi (2007d, p. 8) já havia proposto que lêssemos a expressão política linguística, que hoje - diga-se nomeia uma linha de pesquisa dos estudos da linguagem, como política de línguas, de modo a restituir à língua "um sentido político necessário" à sua constituição enquanto tal. E isso porque não há língua sem inscrição no espaço político (de divisão) de sentidos. Tal inscrição produz, pela imposição de discursos sobre essa língua tomados como verdadeiros, um imaginário de gestão, isto é, de domesticação das diferenças no interior daquilo que se coloca como uma mesma língua. Nesse sentido, tal como propõe a autora, os nomes das línguas recobrem instâncias "em que o seu poder e o modo de sua prática se inscrevem de formas diferentes na sociedade e na história (em) que elas (se) constituem", distribuindo discursividades sobre a(s) língua(s), sobre os sujeitos dessa(s) língua(s) e sobre as relações estabelecidas, não só entre aquela(s) e estes, mas também entre estes.

Se há discursos sobre a língua, há gestos de interpretação, há disputa na/pela língua, pelo direito de nela dizer e de nela/dela ser sujeito. É, pois, sob essa perspectiva, que propomos aqui, pensando a gramática como instrumento não só de manutenção da unidade linguística, mas de estabelecimento/regulação das relações sociais, uma articulação entre política de línguas, o gesto de interpretação procedido pelo sujeitogramático ao se significar como autor e a (re)produção na gramática de um certo imaginário de língua.

\section{Função-autor e imaginário de língua}

A noção de autoria com a qual trabalhamos foi depreendida e deslocada por Orlandi (2007b) a partir da proposta de Foucault (2007, p. 26), para quem o autor pode ser entendido como um "princípio de agrupamento do discurso, como unidade e origem de suas significações, como foco de sua coerência". Distanciando-se da proposta foucaultiana, no entanto, a autoria do ponto de vista discursivo não se restringe a ocasiões especiais em que se dá uma enunciação original, mas ocorre sempre que um sujeito se coloca (supõe estar) na origem do dizer, produzindo um texto com efeito de unidade, coerência, não contradição e fim. Assim sendo, apesar de o autor não instaurar discursividade, ele produz um lugar de interpretação, em meio a outros lugares possíveis. Daí ser a autoria, para nós, uma função exercida pelo sujeito discursivo que se caracteriza pela "produção de um gesto de interpretação" (ORLANDI, 2007b, p. 97), no qual o autor é colocado como o responsável pelo sentido do que diz, do que formula, significando-se e produzindo sentido de acordo com as determinações históricas a que está assujeitado.

\footnotetext{
${ }^{5}$ ibid.

${ }^{6}$ ibid., loc. cit.
} 
Já a noção de imaginário de língua ${ }^{7}$, tal como a temos pensado, relaciona-se à de condições de produção, a qual, conforme Pêcheux ([1969] 2010), é configurada pelo estado de produção dos elementos do discurso. Esses elementos se presentificam no dizer através das formações imaginárias, que dizem respeito ao modo como, a partir de determinados lugares sociais, filiando-se à memória do dizer, em seus gestos de interpretação-autoria, os sujeitos projetam imagens de si, do outro e do objeto do discurso.

Em nossa reflexão, tomando as gramáticas como lugares de materialização de discursos sobre a língua, consideramos que elas se constituem como produtos históricos frutos dos gestos de interpretação procedidos pelos sujeitos-gramáticos que têm, portanto, como objeto do dizer uma certa língua. É, pois, sob essa perspectiva, que trazemos para esta discussão a noção de imaginário de língua na sua relação com a de função-autor. Entendemos que, ao dizer sobre a língua, o sujeito-gramático projeta no discurso uma certa imagem dessa língua de que ele diz dizer, isto é, ele a (res)significa, a partir do lugar que ocupa, filiando-se à memória do discurso gramatical brasileiro, ao mesmo tempo em que se constitui como sujeito (gramático) do seu dizer. O que está em jogo, portanto, como nos lembra Orlandi (2009), não é uma relação termo-a-termo, mas a construção do referente discursivo para o nome língua e, especificamente no caso em análise, para os nomes língua portuguesa ou, simplesmente, português quando significados como patrimônio linguístico e cultural.

\section{Das condições de produção da $1^{\text {a }}$. edição da MGP}

A primeira edição da Moderna Gramática Portuguesa, voltada para o ensino na instituição escolar, foi publicada em 1961, num período em que ainda ressoavam nos estudos linguístico-gramaticais desenvolvidos no Brasil os efeitos decorrentes de dois acontecimentos da década de 50, quais sejam: o início do processo de institucionalização dos saberes filiados à chamada ciência Linguística, notadamente ao que se tinha à época por Estruturalismo, e a implementação, por decreto, da Nomenclatura Gramatical Brasileira (NGB, em 1959) ${ }^{8}$. Esses acontecimentos, como ressalta Orlandi (2002/2009),

\footnotetext{
${ }^{7}$ Orlandi propõe a noção de língua imaginária (ORLANDI; SOUZA, 1988/ ORLANDI, 2002/2008/2009), a qual por vezes retoma como imaginário de língua sem formalizar uma distinção. Entendemos, com Mariani, Medeiros e Moura (2011), que, embora sejam essas noções correlatas e que a noção de língua imaginária pressuponha a sua filiação a um determinado imaginário de língua, estas distinguem-se, pois, enquanto a primeira diz respeito à imagem que comparece nos instrumentos linguísticos de uma dada língua na sua relação com os sujeitos dessa língua, isto é, com os sujeitos que têm/deveriam ter essa língua como sua; a segunda constitui-se como a organização, a sistematização, a normatização (prescrição/imposição de regras, proscrição de usos) de um dado imaginário.

${ }^{8}$ A proposta de unificação e simplificação da nomenclatura gramatical brasileira, considerando que a diversidade no que diz respeito à denominação dos mesmos fatos gramaticais problematizava o ensino de língua portuguesa no país, foi efetivamente implementada em 1959, através da Portaria $\mathrm{N}^{\circ} 36$, de 28 de janeiro. Para tanto, em 1957 já havia sido designada, por meio da Portaria $n^{\circ}$ 152, de 24 de abril, uma Comissão, composta por Antenor Nascentes (nomeado presidente); Clóvis do Rego Monteiro; Celso Ferreira da Cunha; Carlos Henrique da Rocha Lima (nomeado secretário e relator); e Cândido Jucá (Filho) - todos professores catedráticos do Colégio Pedro II, instituição que até então constituía o centro de irradiação de conhecimento sobre a língua do Brasil. Essa comissão desde o início partiu do pressuposto de que as diferentes gramáticas à época abordavam os mesmos fatos gramaticais para os quais davam nomes
} 
tiveram como principal efeito a distinção entre o lugar do gramático e o do linguista e, por conseguinte, o deslocamento da autoridade em relação à produção do saber sobre a língua daquele para este.

A despeito disso, há, na primeira edição da MGP, um "duplo efeito de ruptura e manutenção". Ao mesmo tempo em que, em função da imposição da NGB, rompe-se com os sentidos filiados à tradição gramatical anterior para filiar-se aos sentidos instituídos/legitimados no/pelo discurso oficial, contorna-se tal imposição a partir do argumento do moderno, do novo, compreendido sob essas condições de produção como um argumento de cientificidade. Instaura-se, com isso, um segundo movimento de ruptura, dessa vez em relação à tradição fundada pela NGB, em nome de uma abordagem que considere o que se coloca como "modernos estudos da linguagem" (MGP, 1961, p. 21). Daí tratar-se, como confirmaram as análises por nós desenvolvidas em nossa tese de doutorado, de uma forma de gramática (ORLANDI, 2002) cuja estrutura é cindida, atravessada, de diferentes maneiras, pelos sentidos inscritos no domínio de saber da Gramática e no da Linguística e que, por conseguinte, se constitui no entremeio, no enlace, na tensão, no deslize entre o lugar do gramático e o do linguista.

\section{A língua sobre a qual se diz dizer na $1^{\text {a }}$. edição da MGP}

Salvo no efeito de ambiguidade produzido no título a partir da determinação do substantivo gramática pelo adjetivo portuguesa, que tanto pode designar o nome da língua de que diz a gramática, equivalendo à locução do português, como a sua origem, equivalendo, enquanto adjetivo pátrio, à locução de Portugal, o nome da língua de que se supõe tratar na primeira edição da MGP, "o português", só é dito na página 23 da introdução, mais especificamente nas seções intituladas Que é uma língua e A língua é um fenômeno cultural, das quais recortamos as sequências discursivas ${ }^{9}$ abaixo.

Nessas sequências, dois pontos interligados de imediato se impuseram à nossa leitura: o primeiro, o efeito de sinonímia entre língua e idioma, na sua relação com a concepção de língua enquanto um "sistema de símbolos vocais arbitrários" (MGP, 1961, p. 23) e ao mesmo tempo como "instrumento [de comunicação] particular de um povo

distintos. Esse posicionamento refletiu na nomenclatura oficial, cujo objetivo ficou sendo, então, acabar com a multiplicidade terminológica, adotando a designação que seria, conforme consta nas "Normas Preliminares de Trabalho" estabelecidas pelos membros da Comissão, a "mais exata", a "mais vulgar", a "mais tradicional", a "mais simples" e a "de uso mais geral". Ao determinar os nomes que (não) podem e (não) devem comparecer na gramática, o discurso da NGB se impõe e se sobrepõe ao discurso gramatical brasileiro, silenciando e evidenciando uns sentidos em detrimento de outros. Ao fazer isso, promove uma ruptura na memória do discurso gramatical brasileiro que altera as suas redes de filiações significativas. Como efeito desse silenciamento (ORLANDI, 2007a), então, como propõe Baldini (1999), a NGB promove a regulação da relação do sujeito com o dizível: ela se inscreve no repetível, na memória já existente, elegendo nesta uma região de sentidos possíveis. Tal região se coloca, devido ao efeito da censura imposta pela terminologia oficial, como a única memória possível (de ser lembrada, de ser dita) para o discurso gramatical pós-NGB, impossibilitando, desse modo, que o sujeito se identifique a outros sentidos.

9 As sequências discursivas são, conforme Orlandi (1984), unidades discursivas de textos de natureza variada que se configuram enquanto fragmentos de uma dada situação discursiva postos em correlação conforme a pergunta feita pelo analista, a partir de uma dada posição teórica. 
[...] ou comum a mais de uma nação"10; o segundo, em consequência do primeiro, a sua concepção enquanto algo que é exterior ao homem.

Quadro 1: Imaginário de língua - MGP 1 ${ }^{\mathrm{a}}$. Edição (1961)

SD1: "Entende-se por língua ou idioma o sistema de símbolos vocais arbitrários com que um grupo social se entende.

Uma língua pode ser instrumento particular de um povo único, como acontece com o chinês, o romeno, ou comum a mais de uma nação. Este é o caso do português, que serve a Portugal, ao Brasil e colônias ultramarinas lusas.

Este fato se explica historicamente pelos capítulos de expansão e colonização dos povos. Falamos o português como língua oficial porque, ao lado de outras instituições culturais, os portugueses no-la deixaram como traço de civilização que aqui fundaram depois de 1500". (MGP, 1961, p. 23) [negrito do autor].

SD2: "A língua não existe em si mesma: fora do homem é uma abstração, e no homem é o resultado de um patrimônio cultural que a sociedade a que pertence lhe transmite." (MGP, 1961, p. 23).

No que diz respeito ao primeiro ponto, parece-nos ressoarem aí algumas tensões que já se colocavam naquele que é tomado como o discurso fundador da ciência Linguística moderna, notadamente no Curso de Linguística Geral (1916), cuja autoria é atribuída a Ferdinand de Saussure. Como se sabe, o chamado corte epistemológico se significou na história dos conhecimentos sobre a linguagem como uma cisão desta em língua e fala e, por conseguinte, como uma separação entre aquilo que se toma, respectivamente, como da ordem do social e do individual ${ }^{11}$.

Cabe, no entanto, refletir, ainda que esse não seja o nosso objetivo primário, sobre o efeito de sentido produzido pelo comparecimento da palavra social algumas vezes no Curso. A língua é significada como social porque ela é tomada como "um tesouro depositado pela prática da fala em todos os indivíduos pertencentes à mesma comunidade, um sistema gramatical que existe virtualmente nos cérebros dum conjunto de indivíduos" (CLG, 2006, p. 21) e que "não está completa no cérebro de nenhum", pois se entende que "só na massa ela existe de modo completo"12. Assim, social, no Curso, não diz respeito à relação entre língua e sociedade, mas ao fato de supor-se que a língua, enquanto sistema, encontra-se "depositada" nos cérebros de uma comunidade de indivíduos, opondo-se, assim, à fala, que seria da ordem do indivíduo. Esse sentido atribuído à palavra social no Curso teria sido, inclusive, um dos motivos pelos quais, segundo Colombat, Fournier e Puech (2010), de um modo geral os linguistas da época em que ele foi publicado não lhe teriam dado muita atenção, considerando-o uma especulação demasiadamente abstrata, que não levava em conta o empirismo social, bem como a covariação língua/sociedade, questões que já vinham sendo pensadas, sobretudo, por Antoine Meillet e Joseph Vendryes.

É, pois, essa tensão entre as diferentes formas de se conceber o que se coloca como

\footnotetext{
${ }^{10}$ ibid., loc. cit.

${ }^{11}$ Diz-se no Curso: "Com o separar a língua da fala, separa-se ao mesmo tempo: $1^{\circ}$., o que é social do que é individual; $2^{\circ}$., o que é essencial do que é acessório e mais ou menos acidental" (CLG, 2006, p. 22).

12 ibid., loc. cit.
} 
o aspecto social da língua(gem) que pensamos se fazer significar na primeira edição da MGP a partir da determinação do efeito de sinonímia estabelecido entre língua e idioma - isto é, de uma lado, a língua enquanto sistema de símbolos, uma abstração que "não existe em si mesma" e se dá fora do homem, e, de outro, a língua, enquanto idioma, como instrumento de comunicação com que um grupo social se entende e que tem, portanto, uma função utilitária, já que "serve a Portugal, ao Brasil e colônias ultramarinas lusas" (MGP, 1961, p. 23) [sublinhado meu].

Relacionado a esse primeiro ponto, está, a nosso ver, o segundo, que chamamos de efeito de exterioridade da língua. Esse efeito é produzido na MGP a partir da partição (Milner, 2009) dessa língua que se diz não existir em si mesma em duas dimensões: "fora do homem" e "no homem". No primeiro caso, ela é significada, como vimos, como uma "abstração", sistema de símbolos; no segundo, enquanto "patrimônio cultural", idioma. Assim, mesmo quando "no homem", a língua é tomada como algo exterior a ele, pois é instrumento, e enquanto instrumento pressupõe-se que pode ser controlada, manipulada: ela não só serve a um povo ou a mais de uma nação, como também pode ser deixada de uma nação à outra, o que a caracteriza como patrimônio cultural que a sociedade a que o homem pertence lhe "transmite"13.

Parece-nos haver aí ainda uma con-fusão ${ }^{14}$ entre os sentidos de "grupo social", "povo", "nação" e "sociedade". A língua é tomada como o instrumento com o qual um grupo social se entende, se comunica. Pode ser instrumento particular de um povo ou de mais de uma nação. Ela é transmitida para o homem pela sociedade e, no caso do português, foi deixada para os povos que foram colonizados por Portugal como traço de civilização. Assim temos, de um lado, o que se toma por povo, os chineses, os romenos ${ }^{15}$ e os povos que foram colonizados por Portugal; de outro, o que se toma por nações: Brasil e Portugal. O Brasil também foi colonizado, mas, quando o foi, ainda não era Brasil, não era Nação, era povo. Nação se tornou depois, depois de 1500, após passar pelo processo civilizatório iniciado com a colonização de Portugal, que já era Nação. Ao lado dessas duas nações, Brasil e Portugal, há as então chamadas colônias ultramarinas lusas, que à época da publicação da $1^{\text {a }}$. edição da MGP não eram nações (ainda), eram colônias de Portugal, povos que se encontrariam, então, em processo civilizatório.

Essa con-fusão entre os sentidos de nação e povo traz à baila, portanto, uma tensão que comparece no dizer do gramático entre unidade e diversidade. Enquanto ao se dizer povo, contraditoriamente, coloca-se em questão a diversidade - a diversidade dos povos

\footnotetext{
13 ibid., loc. cit.

14 Ou seja, uma fusão e uma confusão (ORLANDI, 2008).

15 Poderíamos pensar aqui a diversidade constitutiva do que é posto como língua chinesa, o chinês, que é constituído por quatro línguas distintas - o mandarim, o cantonês, o sichuanês e o hakka - que têm em comum apenas a origem sino-tibetana e a representação escrita, ou do que se toma por povo chinês, os chineses, e da China, que, desde 1949, se divide em duas repúblicas, a República Popular da China (RPC) e a República da China (RC), que são igualmente independentes e que também igualmente não reconhecem a legitimidade uma da outra. Também poderíamos pensar a diversidade constitutiva do romeno, língua oficial da Romênia (e atualmente de outros quatro países nos quais divide espaço com outras línguas também oficiais), que se diz ser constituído por quatro dialetos e que vive em tensão desde sempre com outras línguas, como, por exemplo, o antigo maldávio, nome da língua oficial da Maldávia até 2013, quando, por ser considerado a mesma língua, passou, por lei, a ser chamado também de romeno.
} 
que habitam o que se toma por uma mesma região, a diversidade dos povos que são falantes daquilo que é posto como uma língua única, a diversidade dessa língua e das línguas com que ela está em contato -; ao se dizer nação, silencia-se essa diversidade e impõe-se um imaginário de unidade do que é posto como língua, cidadão e Estados nacionais. E é aí que, para nós, esse imaginário de língua fura, falha.

Ao lado dos sentidos de povo e de nação são colocados, como vimos, o de grupo social e sociedade: o português, enquanto instrumento de comunicação, isto é, em sua dimensão posta como idiomática, serve a Portugal, ao Brasil e às colônias ultramarinas lusas; logo, estes constituiriam um grupo social que se entende, que se comunica. Se a língua é transmitida ao homem pela sociedade a que ele pertence, no caso do brasileiro, que sociedade seria essa? Como pensar os sentidos de grupo social e de sociedade em relação ao de nação(ões)?

A nosso ver, a con-fusão entre esses sentidos opera um silenciamento das diferenças sociais, culturais e linguísticas entre Portugal, Brasil, as chamadas colônias ultramarinas e também entre estas, pois toma todos como se fossem um, uma só sociedade, um só grupo social, um todo homogêneo, ainda que se reconheçam diferenças políticas, ainda que nem todos nesse todo tenha o status de Nação, ainda que a história (nada pacífica) do processo de independência brasileira também seja apagada, assim como o foi a resistência à dominação portuguesa nas chamadas colônias ultramarinas, ainda que... São muitos "ainda que", e é justamente neles que reside o silêncio, isto é, essa possibilidade, segundo Orlandi (2007a), de, conforme a determinação históricoideológica do sujeito (gramático), os sentidos serem sempre outros, mas de, justamente por poderem, não o serem. O que é dito e o que não se diz entram em tensão, disputam espaço, se con-fundem, de modo que o que não é dito se faz significar, faz fissura no dizer, nele deixa suas marcas. Trata-se, pois, de um silenciamento constitutivo ${ }^{16}$ do discurso gramatical brasileiro de meados do século XX, silenciamento este necessário à imposição e à manutenção do imaginário de unidade linguística.

Esse imaginário, atravessado pelo discurso do colonizador português, coloca Portugal como centro irradiador de civilização e de cultura: o português nos fora deixado por Portugal, "ao lado de outras instituições culturais", como "traço da civilização que aqui fundaram depois de 1500" (MGP, 1961, p. 23). Assim, ao se relacionar o sentido de língua ao de civilização, como nos lembra Guimarães (2011), mobiliza-se um tempo futuro para essa língua, o qual está associado ao imaginário de evolução e progresso e tem como marco inicial o ano de 1500, momento em que essa língua nos teria sido "transmitida". Apagam-se o processo de historicização da língua do Brasil e a história da relação dos sujeitos brasileiros com a sua língua e, com isso, reforça-se a ilusão de unidade linguística entre os dois países. Contribui para a manutenção dessa ilusão ainda a relação estabelecida entre os sentidos de civilização e cultura. Ao significar a língua como um patrimônio, uma instituição cultural traço da civilização fundada pelos portugueses, apagam-se ainda outras manifestações culturais não institucionalizadas e, consequentemente, as demais línguas em circulação em solo nacional.

${ }^{16}$ id., ibid. 


\section{Das condições de produção da $37^{a}$. edição da MGP}

A MGP teve trinta e seis edições sem grandes modificações (Dias; Bezerra, 2006) até ser publicada em 1999 a sua $37^{\mathrm{a}}$. edição, a qual, embora nela não seja dito, diferentemente das edições anteriores, tem como espaço de circulação, não a instituição escolar, mas a universidade. Tendo em vista que, como pontua Orlandi (2002, p. 149), toda forma de gramática traz inscrito um efeito-leitor ${ }^{17}$ "de que deriva (ou determina) seu uso", entendemos que é esse deslocamento que produz/permite produzir um efeito de amadurecimento no dizer do gramático que se coloca desde o prefácio, no qual se apaga a referência à NGB e se afirma tratar-se de um "livro novo" amadurecido pela "leitura atenta dos teóricos da linguagem" (MGP, 1999, p. 19). Esse efeito é significado, em seguida, como da ordem da atualização e do enriquecimento: "atualização no plano teórico da descrição do idioma e enriquecimento por trazer à discussão e à orientação normativa a maior soma possível de fatos gramaticais" ${ }^{\prime 18}$.

Em nossa leitura do prefácio da $37^{\mathrm{a}}$ edição, portanto, depreendemos sentidos que sinalizavam que havia no corpo dessa gramática, assim como ocorre na primeira edição, um atravessamento entre saberes filiados ao lugar do gramático ("orientação normativa") e ao do linguista ("plano teórico da descrição"), lugares estes que nestas condições de produção ganham novos contornos. Para justificar tal atravessamento, que, como nos foi possível concluir a partir das análises depreendidas, se faz significar em toda a gramática, recorre-se, já no prefácio da $37^{\mathrm{a}}$ edição, mais uma vez, ao argumento do novo, da cientificidade, embora o novo aqui não signifique o mesmo que outrora.

Como se sabe, na década de 1960, na Europa e nos Estados Unidos, houve uma ebulição de teorias linguísticas que se propunham a pensar, dentre outros, a comunicação e a interação oral e escrita, a diversidade linguística e a construção do sentido. Essas teorias chegaram ao Brasil na década de 1980 e, embora tenham, no espaço universitário, de certo modo progressivamente se sobreposto aos estudos significados como formais, com eles passaram a conviver de forma tensa. Assim, se na primeira edição o que se toma por saber linguístico está filiado ao que se tinha à época por Estruturalismo, na $37^{\mathrm{a}}$ edição, como efeito das condições de produção em que se encontram os estudos sobre a linguagem no Brasil, comparecem saberes filiados, não só ao que nesse momento se coloca como Estruturalismo, mas também à chamada Linguística Textual, à Sociolinguística e ao Funcionalismo, notadamente àquele ao qual se filiam os estudos filiados ao nome de autor Eugenio Coseriu.

\footnotetext{
${ }^{17}$ O lugar de autoria, como nos lembra Orlandi (2007b, p. 74), "se faz com a constituição de um lugar de interpretação definido pela relação com o Outro (o interdiscurso) e com o outro (o interlocutor)", que em $\mathrm{AD}$ chamamos de efeito-leitor. Assim, continua a autora, "o lugar do autor é determinado pelo lugar de interpretação. O efeito-leitor representa, para o autor, a sua heterogeneidade constitutiva (memória do dizer, repetição histórica)" (ibid., p. 75). O autor, portanto, como nos explica a autora, não só não pode simplesmente dizer coisas que não tenham sentido, isto é, que não façam parte do interdiscurso, como deve dizer coisas que façam sentido para o seu leitor (ou melhor, para aquele que imagina que seja o seu leitor). A noção de efeito-leitor está, pois, relacionada à de formações imaginárias proposta por Pechêux ([1969] 2010), sobre a qual discorremos anteriormente. Quando da produção de um texto, produz-se, como vimos, além de uma imagem do objeto do discurso e do autor a quem o texto é atribuído, uma imagem de leitor a quem este se dirige.

18 ibid., loc. cit.
} 


\section{A língua sobre a qual se diz dizer na $37^{\text {a }}$ edição da MGP}

Diferentemente do que vimos na edição de 1961, nessa edição o nome da língua de que supõe dizer a gramática comparece já no prefácio: "língua portuguesa", sendo ela tomada ao mesmo tempo como "traço de nacionalidade" - cabendo aqui perguntar: de que nação?, já que esta não é determinada ${ }^{19}$ - e "elo fraterno da lusofonia" ${ }^{20}$. No que diz respeito a este último, chamemos aqui atenção para o deslocamento no relacionamento estabelecido entre os povos ditos lusófonos. Na primeira edição da MGP, como vimos, diz-se que a língua significada como patrimônio cultural foi deixada pelos portugueses ao Brasil e às colônias ultramarinas lusas. Àquela época estas ainda não haviam conquistado a sua independência política, não eram civilizações, mas povos, daí a sua significação como colônias. Em 1999, no entanto, Angola, Cabo Verde, Guiné-Bissau, Moçambique e São Tomé e Príncipe ${ }^{21}$ já se encontravam independentes politicamente, sendo ressignificados no dizer do gramático: não se trata mais de colônias de Portugal, mas de nações-irmãs.

Seguem o prefácio da $37^{\mathrm{a}}$ edição o prefácio da primeira e uma introdução que se subdivide em dois subcapítulos intitulados: "Breve história externa da língua portuguesa" e "Teoria gramatical". Partiremos nossa análise do primeiro, do qual recortamos a sequência abaixo:

\section{Quadro 2: Imaginário de língua - MGP 37ª . Edição (1999)}

SD3: "Do ponto de vista linguístico, o português contemporâneo, fixado no decorrer do séc. XVIII, chega ao século seguinte sob o influxo de novas idéias estéticas, mas sem sofrer mudanças no sistema gramatical que lhe garantam, neste sentido, nova feição e nova fase histórica.

Os escritores dos séculos XIX e XX de todos os quadrantes da Lusofonia souberam garantir esse patrimônio linguístico herdado de tanta tradição literária.

Em Portugal, no Brasil, em Angola, Cabo Verde, Guiné-Bissau, Moçambique, São Tomé e Príncipe, a língua portuguesa, patrimônio cultural de todas estas nações, tem sido, e esperamos seja por muito tempo, expressão da sensibilidade e da razão, do sonho e das grandes realizações.

Patrimônio de todos e elo fraterno da Lusofonia de cerca de 200 milhões de falantes espalhados por todos os continentes [...]" (MGP, 1999, p. 27).

Em "Breve história externa da língua portuguesa", o que se conta como história da língua confunde-se com a história de Portugal. A língua nomeada portuguesa é significada como "uma continuação ininterrupta, no tempo e no espaço, do latim" (MGP, 1999, p. 23). Este, levado, no início do séc. III a.C., à Península Ibérica pela expansão românica, tornou-se, no século XII d.C., aquilo que seria o "falar comum à Galiza e ao

\footnotetext{
19 A referência ao Brasil no prefácio comparece apenas uma vez a partir do adjetivo brasileiros, que determina os centros universitários em que se encontram "nossos melhores linguistas" que seguem "outros modelos [teóricos]", os quais, apesar de "válidos", não constituem o "arcabouço teórico" da 37. Edição da MGP (1999, p. 19).

20 ibid., p. 20.

${ }^{21}$ Guiné-Bissau conquistou a sua independência em 1973; e Moçambique, São Tomé e Príncipe, Cabo Verde e Angola, em 1975.
} 
território Portucalense". Anos mais tarde, no período das grandes navegações, essa língua já então chamada portuguesa, "companheira do império", foi levada, com o movimento de expansão marítima, colonial e religiosa, "na palavra dos indômitos marinheiros, pelos mares nunca d'antes navegados"22, àquelas que eram até então tidas como "regiões incógnitas", "o fim do mundo"23. Diz-se, ainda, que o que se tem hoje por "português contemporâneo" 24 se fixou no século XVIII e, apesar de ter estado sob o influxo do que se toma por "novas idéias estéticas", chegou ao século seguinte "sem sofrer mudanças no sistema gramatical" 25 , de modo que os escritores "de todos os quadrantes da lusofonia", nos séculos XIX e XX, apenas "garantiram" - mantiveram, já que nada mudou - "esse patrimônio linguístico de tanta tradição literária" 26 .

$\mathrm{Na} 37^{\mathrm{a}}$. edição, assim como na primeira, como podemos notar, mantém-se o imaginário de exterioridade da língua em relação ao homem - ela pode ser levada de um lugar para o outro, até o fim do mundo. Da mesma forma, exterior, "externa", é a história dessa língua que, apesar de ter sido "levada" para outros lugares, de ser falada por outros sujeitos, em outros tempos-espaços, permanece a mesma, homogênea, desde o século XVIII. Segundo essa breve história, portanto, a língua nomeada portuguesa, falada por "cerca de 200 milhões de falantes espalhados por todos os continentes", é uma e una em todas as nações ditas lusófonas, "patrimônio linguístico herdado" por essas nações e, ao mesmo tempo, "elo fraterno" entre elas ${ }^{27}$.

No subcapítulo "Teoria Gramatical”, a definição de língua é atravessada por discursos da Sociolinguística e do Funcionalismo - este último através do mecanismo de citação dos dizeres filiados ao nome de autor Eugenio Coseriu. Nele, a língua é dividida em duas dimensões: a chamada língua histórica, significada como produto cultural e histórico reconhecido tanto por falantes nativos quanto por falantes de outros idiomas; e a chamada língua funcional, significada como aquela que é objeto da descrição estrutural e funcional.

Sobre a chamada língua histórica, diz-se ainda que se trata de "um amplo e diversificado espaço cultural" que encerra em si "várias tradições linguísticas, de extensão e limites variáveis, em parte análogas e em parte diversas, mas historicamente relacionadas" 28 . Essas variações são tomadas como analogias e divergências fonéticas, gramaticais e léxicas, de modo que se conclui que uma língua histórica comporta sempre "um conjunto de sistemas" que variam de acordo com o espaço geográfico (variações diatópicas), o nível sociocultural (variações diastráticas) e o estilo (variações diafásicas). Sob essa perspectiva, a língua nomeada portuguesa é, então, significada como uma língua histórica, que é "constituída de várias 'línguas' mais ou menos próximas entre si, mais ou menos diferenciadas, mas que não chega a perder a configuração do que se trata 'do português"'29.

\footnotetext{
22 ibid., p. 24.

${ }^{23}$ ibid., loc. cit.

24 ibid., p. 27.

${ }^{25}$ ibid., loc. cit.

${ }^{26}$ ibid., loc. cit.

27 ibid., p. 27.

28 ibid., p. 37.

${ }^{29}$ ibid., p. 50.
} 
Uma vez que se entende que uma língua histórica é composta por um conjunto de sistemas, conclui-se que, num texto oral ou escrito, apesar de sempre haver uma língua funcional que se sobreponha às demais, podem comparecer, em função dos destinatários, do objeto e da situação, diferentes línguas funcionais, de modo que "todo falante de uma língua histórica é plurilíngüe, porque domina ativa ou passivamente mais de uma língua funcional, embora não consiga saber toda a extensão de uma língua histórica"30.

No que concerne à língua funcional, ela se estruturaria ainda em sistema e norma, sendo que o primeiro diria respeito ao que se toma por "oposições funcionais", "traços distintivos necessários para que uma unidade da língua [...] não se confunda com outra unidade" 31 ; e a segunda, ao que é posto como "tradicional, comum e constante, ou, em outras palavras, tudo o que se diz 'assim, e não de outra maneira" 32 , podendo coincidir com o sistema "quando este oferece uma só possibilidade de realização" "33. Para ilustrar essa distinção, coloca-se, por exemplo, que, "o sistema do português conta com o sufixo -ção, além de outros, para formar substantivos, em geral denotadores de ação, oriundos de verbos", mas "a norma prefere casamento a casação, livramento a livração, tomada a tomação ou tomamento" 34 . Assim, o efeito de distinção entre sistema e norma é produzido a partir do que se toma como uma possibilidade de "criatividade", de "novidade" de criação ${ }^{35}$, que se concebe como inerente ao primeiro e inexistente na segunda, a qual seria, portanto, da ordem da estagnação, da estabilização, da constância. Talvez, por isso, isto é, levando em consideração a sua dimensão normativa, apesar de considerar-se a multiplicidade da língua funcional, diz-se também, contraditoriamente, que ela se apresenta, diferentemente da língua histórica, como "uma realidade linguística idealmente homogênea e unitária, isto é, que se apresenta sintópica, sinstrática e sinfásica" ${ }^{\prime 3}$.

Dessa maneira, entende-se que a variação é, pois, sempre a variação possível pelo conjunto de sistemas que constituem a chamada língua histórica, ressaltando-se que a esse conjunto sobrepõe-se o que é tomado como a norma da língua, já que se diz que esta "tem maior amplitude", embora aquele seja "mais amplo" em função da sua possibilidade de criação $^{37}$. Se, por um lado, então, a língua histórica, enquanto produto histórico, pressupõe o que é posto como diversidade; por outro lado, a língua funcional, tanto na sua dimensão dita sistemática quanto na normativa, é o que garante, de diferentes maneiras, a essa língua (a ilusão de) unidade. Enquanto o conjunto de sistemas impede que variações não previstas se realizem, a norma, sobrepondo-se a ele, é significada como uso exemplar ${ }^{38}$, como "plano da estruturação do saber idiomático que está mais próximo

\footnotetext{
30 ibid., p. 38.

31 ibid., p. 42.

32 ibid., loc. cit.

33 ibid., p. 43.

${ }^{34}$ ibid., loc. cit.

35 ibid., loc. cit.

36 ibid., p. 38.

37 ibid., p. 43

${ }^{38}$ A gramática normativa é significada como aquela que "elenca os fatos recomendados como modelares da exemplaridade idiomática para serem utilizados em circunstâncias especiais do convívio social" (MGP, 2009, p. 52).
} 
das realizações concretas" 39 , e projeta-se sobre a língua, tornando-se a parte visível desta, isto é, um modelo a ser seguido pelos falantes das comunidades integrantes do que se diz ser um mesmo domínio linguístico. Com isso, a norma impõe à língua estagnação e, por conseguinte, estabilidade de modo a (supostamente) preservar características que garantam a sua singularidade perante os falantes nativos e os falantes dos demais idiomas.

É sob essa perspectiva que se torna possível ao gramático afirmar que "Há uma diversidade na unidade, e uma unidade na diversidade" (MGP, 1999, p. 50) [itálicos do autor], sendo a diversidade tomada como essa possibilidade de realizações determinadas pelo sistema ao qual se sobrepõe a norma, que, por sua vez, como vimos, é significada como aquilo que sustentaria o efeito de unidade. Não há lugar, portanto, nesse imaginário, para a diversidade como mudança, como o outro; somente como variação, como o mesmo. É assim que, voltando à análise da sequência extraída do subcapítulo "Breve história" (SD3), a diversidade é concebida como mudança do latim até o que se coloca como "português contemporâneo", mas depois disso ela é significada como variações estéticoexpressivas, como possibilidades linguísticas que se inscrevem nisso que se concebe como língua histórica e que não afetam o que se tem por sistemático/normativo.

Nesse sentido, o que é posto como teoria gramatical comparece na $37^{a}$ edição da MGP como argumento que legitima o imaginário de homogeneidade linguística entre os países que têm a língua nomeada portuguesa como língua oficial, imaginário este que, segundo Orlandi (2009), é sustentado pela noção de lusofonia, a qual alimenta ainda o repertório da colonização, que tem como referência Portugal. Tal imaginário é também reiterado, segundo Branco (2013), pela significação dessas nações como irmãs: elas falam a mesma língua, o português, e têm uma história comum, pois se constituem como extensões de Portugal. Assim, apesar de esse elo fraternal supor uma relação de igualdade entre essas nações, faz-se significar aí uma relação hierárquica que se funda na contradição engendrada no processo de colonização. Portugal, a nosso ver, não é um irmão, mas o pai (ou seria um padrasto?) que deixou como "patrimônio" essa língua una para os seus filhos, as nações por ele colonizadas; estas, sim, postas como irmãs. Nesse suposto espaço lusófono - tal como pensado por Branco (2013) -, portanto, o imaginário de língua se constrói tendo como referência essa língua do pai, e não as dos fillhos, de modo que a heterogeneidade constitutiva das línguas destes, as demais línguas faladas nesses diferentes espaços nacionais, bem como as diferenças entre estes, são/precisam ser silenciadas em prol desse imaginário de língua comum, que silencia ainda, como nos lembra Branco ${ }^{40}$, "a violência (da colonização) que está na origem dessa família".

\section{Patrimônio linguístico e cultural: algumas considerações a título de fechamento}

Conceber a língua como patrimônio implica, como podemos depreender a partir de Venturini (2009), o retorno a um passado, que se organiza como uma narrativa aparentemente coerente, na qual é apagado o que deve ser esquecido e, por conseguinte,

\footnotetext{
${ }^{39}$ ibid., p. 42.
}

40 ibid., p. 150. 
o que não pode e não deve ser lembrado, pressupondo-se, com isso, a partir do controle do passado, controlar-se também o presente. É assim que a língua nomeada portuguesa ou simplesmente português, significada como idioma, passa a constituir-se como monumento, como lugar de memória, de comemoração (ZOPPI-FONTANA, 2009) disso que hoje é posto como a lusofonia ${ }^{41}$ que nos une.

Apesar de na edição de 1999 não haver o efeito de con-fusão entre os sentidos de povo, nação, grupo social e sociedade, como vimos na edição de 1961, nela, ao se significar os países ditos lusófonos como nações-irmãs, também se silencia as diferenças constitutivas destes, entre estes e também de e entre sua(s) língua(s). Lembremos aqui que desde o prefácio a língua nomeada portuguesa é posta, ao mesmo tempo, como "traço de nacionalidade" e como "elo fraterno da lusofonia", mas é silenciada a nacionalidade a que ela se refere, pois, dizê-lo implicaria contradizer o imaginário imposto pela noção de lusofonia, que pressupõe a existência de uma única língua pertencente a diferentes nações e que, portanto, se constituiria como traço de nacionalidade não de uma, mas de todas elas. Assim, ao se significar a língua nomeada portuguesa como "patrimônio de todos", de modo a pressupor-se uma total inclusão dos sujeitos, silencia-se ainda que ela, tal como sublinha Branco (2013), não é de todo mundo, isto é, de todos os cidadãos dos países ditos lusófonos, e que esse discurso da lusofonia também não é para todos, mas para alguns: "para os que falam e escrevem a língua imaginária portuguesa da lusofonia [...]"42.

Parafraseando Zoppi-Fontana ${ }^{43}$, admitir a diversidade, embora coloque como pressuposto a igualdade, não apaga a desigualdade. E é pelo viés da diversidade cultural e linguística, via discurso da Sociolinguística e do Funcionalismo, que se busca, como vimos, na $37^{\mathrm{a}}$ edição, apaziguar os sentidos de diferença que colocam em questão a desigualdade que está na origem dessa família - isto é, desde o processo de colonização que, como assinalou Branco (2013), foi marcado pela violência - e que se perpetua até hoje em relação aos lugares ocupados por essas diferentes nações no que tange à produção de conhecimento linguístico-gramatical, ao direito à/sobre essa língua e aos modos de nela dizer.

Se na $1^{a}$. edição a relação entre língua e cultura relaciona-se ao sentido de civilização, na $37^{\text {a }}$. ela se constitui como um efeito do recrudescimento do discurso sobre a(s) língua(s), que, com o desenvolvimento do sociologismo e sob a ideologia do culturalismo, conforme Orlandi (2009), ocorreu a partir do final do século XX. Nessa perspectiva, diz-se priorizar o multilinguismo - como vimos, na edição de 1999, colocase que a chamada língua histórica encerra "várias tradições linguísticas" -, ao mesmo tempo em que se apagam as diferenças históricas: aceitam-se "todas as culturas e línguas, enquanto, em outro lugar, aquele que se sustenta na estrutura de poder que realmente decide, somos dominados pelo monolingüismo" ${ }^{44}$, monolinguismo este que, no caso em

\footnotetext{
${ }^{41}$ O termo lusofonia, como pontua Branco (2013), foi cunhado em 1950, mas ganhou maior projeção no final dos anos 90, com a criação da Comunidade de países lusófonos - CPLP (1996).

42 ibid., p. 138.

${ }^{43}$ Em conferência proferida na mesa-redonda intitulada "Ensino do PLE- PLH e Políticas Linguísticas" no V SIMELP, realizado em Outubro de 2015, em Lecce (Itália).

44 ibid., p. 163. Ao refletir sobre esse imaginário de monolinguismo, Orlandi (2009) refere-se ao inglês, mas acreditamos que essa reflexão se aplica também à relação estabelecida no espaço dito lusófono entre a língua nomeada portuguesa e as línguas outras que habitam esse espaço.
} 
análise, é imposto pela noção de lusofonia, que silencia as diferenças a partir da projeção de um imaginário de língua que tem como referência uma certa norma de Portugal. "O Luso é o Português. - diz Orlandi ${ }^{45}$. - Nada temos a ver com isso".

Desse modo, embora tenham funcionamentos distintos, nas duas edições da MGP, é a significação da língua imaginária portuguesa enquanto idioma compartilhado entre nações (1999) ou entre nações e povos (1961) o que produz aquilo que Dias (1996) designou como efeito de idiomaticidade. Esse efeito - que se relaciona de forma tensa com o que seria tomado como da ordem da língua e se materializa, na $1^{a}$ edição, a partir da partição da língua em sistema e idioma e, na $37^{a}$ edição, em língua funcional e língua histórica - impõe um imaginário de unidade, de espaço/tempo comuns, que afeta os sujeitos falantes, produzindo um efeito de identidade entre estes e essa língua que lhes é dada historicamente como sua. Para tanto, porém, silencia-se a história da colonização imposta ao Brasil e aos demais países ditos lusófonos, o processo de historicização da(s) língua(s) nesses diferentes espaços de enunciação (GUIMARÃES, 2005) ${ }^{46}$, bem como a história da relação estabelecida entre esta(s) e os sujeitos desses espaços. O imaginário de língua, na sua relação com a língua imaginária, em ambas edições, é, pois, (ainda) atravessado pelo discurso do colonizador português. Além disso, nelas, o que se toma por ciência linguística comparece, já na introdução, como calção que sustenta "cientificamente" - a (ilusão de) unidade e de homogeneidade linguística entre diferentes nações/povos.

A língua tomada como patrimônio é, nesse sentido, significada no encontro dos discursos sobre a língua (da Gramática e da(s) Linguística(s)) com o discurso político (isto é, da política) e, como pontuou Venturini (2009), com os discursos jurídico e antropológico - este último, na $1^{\mathrm{a}}$. edição, a partir da concepção de língua como instituição cultural transmitida ao homem pela sociedade a que pertence e, na $37^{\mathrm{a}}$. edição, como vimos com Orlandi (2009), sob a ideologia do culturalismo. É, pois, como efeito desse encontro, que, na edição de 1961, pensamos ser possível interpretá-la como um objeto passível de ser 'transmitido' (discurso jurídico), 'deixado' pelos portugueses, uma "instituição cultural" (discurso antropológico) de propriedade do povo colonizador que se estende às nações/povos por ele colonizadas como 'traço de civilização' que projeta para estes um futuro de evolução e progresso, ao mesmo tempo em que são apagadas as suas especificidades (discurso político). E ainda, na edição de 1999, como 'herança' (discurso jurídico), um 'patrimônio cultural' (discurso antropológico) herdado, cuja propriedade inicial é apagada - já que se diz apenas que "Os escritores dos séculos XIX e XX de todos os quadrantes da Lusofonia souberam garantir esse patrimônio linguístico herdado de tanta tradição literária" (SD3), omitindo-se a quem pertenceria inicialmente tal patrimônio - em prol da imposição de um imaginário de unidade linguística que se associa a um imaginário de igualdade entre as nações ditas lusófonas, promovendo a ilusão de que, à medida em que a língua imaginária portuguesa se projeta no cenário internacional, projetam-se também as nações que ela imaginariamente representa

\footnotetext{
45 ibid., p. 179.

${ }^{46}$ A noção de espaço de enunciação, tal como proposta por Guimarães (2005), está diretamente relacionada à noção de político com que trabalhamos. Ela diz respeito à relação estabelecida entre as línguas e os falantes, sendo aquelas tomadas enquanto espaços divididos pelo político no qual "habitam" os falantes que disputam o direito ao dizer e aos modos de dizer.
} 
(discurso político).

Nos sentidos produzidos para o nome língua portuguesa, nas diferentes conjunturas em análise, a partir desses encontros está inscrito, portanto, impreterível e incontornavelmente o político. Lembremos aqui as palavras de Orlandi (2007d) ao reivindicar a restituição de um sentido político necessário à constituição da língua enquanto tal, tendo em vista a sua impossibilidade de existir sem que se inscreva no espaço político (de divisão) de sentidos. É a partir dessa inscrição que evidências são impostas e as disputas entre e pelas línguas, isto é, pelos modos e pelo direito de nelas dizer, bem como entre os sujeitos que a elas se identificam para se constituírem enquanto tais, são silenciadas, promovendo a manutenção do imaginário de língua única e una entre os diferentes povos/nações que têm a língua chamada portuguesa como oficial.

Cabe acrescentar aqui que é a escola, enquanto lugar de transmissão de uma certa língua, a responsável pela disseminação das discursividades (re)produzidas, nas/pelas gramáticas brasileiras, já que estas afetam a prática docente e o ensino de língua materna, passando a constituí-los. Daí fazer-se preciso, conforme pontuou Orlandi (1998), haver o fortalecimento de uma postura ética - no sentido proposto pela autora, isto é, enquanto reflexão científica sobre o modo de (re)produção do conhecimento linguístico em nossa sociedade - do professor frente à gramática e aos saberes que nela se inscrevem. Esperamos ter com este trabalho contribuído para isso. $\mathrm{O}$ discurso gramatical, como temos buscado demonstrar em nossas pesquisas, tem como efeito a opacificação de saberes (terminologias, conceitos, regras) e, por conseguinte, a (re)produção e a imposição, inclusive no que diz respeito à relação entre imaginário de língua e língua imaginária, de certas evidências que são tomadas por professores e alunos como verdades inquestionáveis e que acarretam uma oposição simplista entre certo e errado, culto e inculto, normal e anormal, a qual, por sua vez, tem como efeito não só a legitimação e a marginalização de determinados modos de dizer, como também de sujeitos a esses modos identificados.

\section{Referências Bibliográficas}

AUROUX, S. A revolução tecnológica da gramatização (1992). Trad. Bras. 2a . ed. Campinas, SP: Editora da UNICAMP, 2009.

BALDINI, L.J.S. A nomenclatura gramatical brasileira interpretada, definida, comentada e exemplificada. Dissertação. Mestrado em Linguística. IEL, Unicamp, Campinas, SP, 1999.

BRANCO, L.K.A.C. A língua em além-mar: sentidos à deriva - o discurso da CPLP sobre língua portuguesa. Tese. Doutorado em Linguística, Instituto de Estudos da Linguagem, Universidade Estadual de Campinas, Campinas, 2013.

BECHARA, E. Moderna Gramática Portuguesa. $37^{\mathrm{a}}$. ed. rev. e amp. Rio de Janeiro: Lucerna, 1999. 
Moderna Gramática Portuguesa (curso médio) - com base na Nomenclatura Gramatical Brasileira. 1 ${ }^{\mathrm{a}}$ ed. São Paulo: Companhia Editora Nacional, 1961.

COLOMBAT, B.; FOURNIER, J.M.; PUECH, C. Histoire des idées sur le langage et les langues. Paris: Kliincksieck, 2010.

DIAS, L.F. Gramática e política de língua: institucionalização do lingüístico e constituição de evidências lingüísticas. Em: ORLANDI, E.P. (Org.). Política lingüística no Brasil. Campinas: Pontes, 2007. 183-200.

Os sentidos do idioma nacional: as bases enunciativas do nacionalismo lingüístico no Brasil. Campinas (SP): Pontes, 1996.

; BEZERRA, Maria Auxiliadora. Gramática e dicionário. Em: GUIMARÃES, E.; ZOPPI-FONTANA, M.G. (Orgs.). Introdução às ciências da linguagem: a palavra e a frase. Campinas: Pontes, 2006. 11-37.

FOUCAULT, Michel. A ordem do discurso. 15ª ed. São Paulo: Loyola, 2007.

GUIMARÃES, E. Os sentidos e a política de uma palavra da ciência. Em: ZANDWAIS, A.; ROMÃO, L.S. Leituras do político. Porto Alegre: Editora da UFRGS, 2011. 83-104.

Semântica do acontecimento. Campinas, SP: Pontes, 2005.

MARIANI, B.; MOURA, T.; MEDEIROS, V. Habitar uma teoria. Em: CASTELLO BRANCO, L.; RODRIGUES, E.; SANTOS, G. Análise de discurso no Brasil: pensando o impensado sempre. Uma homenagem a Eni Orlandi. Campinas: RG, 2011. 293-310.

MILNER, Jean-Claude. L'amour de la langue. France: Éditions Verdier, 2009.

ORLANDI, E.P. Língua Brasileira e outras histórias - Discurso sobre a língua e ensino no Brasil. Campinas: Editora RG, 2009.

Terra à vista - Discurso do confronto: velho e novo mundo. $2^{\mathrm{a}}$. ed. Campinas, SP: Ed. da Unicamp, 2008.

As formas do silêncio. $6^{\text {a }}$. ed. Campinas, SP: Editora da Unicamp, 2007a.

Interpretação; autoria, leitura e efeitos de trabalho simbólico. $5^{\mathrm{a}}$. ed. Campinas, SP: Pontes Editores, 2007b. $\overline{2007 c}$.

Análise de Discurso - princípios e procedimentos. $7^{\text {a }}$. ed. Campinas, SP: Pontes,

Apresentação. Em: ORLANDI, E. (Org.). Política linguística no Brasil. Campinas, SP: Pontes, 2007d. 
ORLANDI, E.P. Língua e conhecimento linguístico: para uma história das ideias no Brasil. São Paulo: Cortez, 2002.

. Ética e política linguística. Língua e instrumentos linguísticos, 7-16, 1998. 1984. . Segmentar ou recortar. Linguística [questões e controvérsias], Uberaba, 9-26,

ORLANDI E.P.; DE SOUZA, T.C.C. A língua imaginária e a língua fluida: dois métodos de trabalho com a linguagem. Em: ORLANDI, E.P. (Org.). Política linguística na América Latina. Campinas: Pontes, 1988.

PÊCHEUX, M. Análise automática do discurso (AAD-69) (1969). Em: GADET, F.; HAK, T. Por uma análise automática do discurso. Uma introdução à obra de Michel Pêcheux. Campinas: Ed. UNICAMP, 2010. 61-161.

Semântica e discurso: uma crítica à afirmação do óbvio (1975). $4^{\mathrm{a}}$. ed. Campinas, SP: Editora da Unicamp, 2009.

SAUSSURE, F. Curso de linguística geral (1916). 27ª ed. São Paulo: Cultrix, 2006.

SÉRIOT, P. Proposições para uma escritura da história da linguística soviética: a noção de "discurso sobre a língua". Cad. Est. Ling., Campinas, (24), 131-149, jan/jun 1993.

VENTURINI, M.C. Imaginário urbano: espaço de rememoração/comemoração. Passo Fundo: UPF Editora, 2009. 28-228.

ZOPPI-FONTANA, M.G. O português do Brasil como língua transnacional. Em: ZOPPIFONTANA, M.G. (Org.). O português do Brasil como língua transnacional. Campinas: Editora RG, 2009. 13-41.

Artigo recebido em: dezembro de 2016.

Aprovado e revisado em: fevereiro de 2016.

Publicado em: abril de 2017.

Para citar este texto:

COSTA, Thaís de Araújo da. Evanildo Bechara e A(s) Moderna(s) Gramática(s) Portuguesa(s): reflexões sobre a inscrição do político no imaginário de língua instituído na/pela gramática brasileira. Entremeios [Revista de Estudos do Discurso, on-line], Seção Temática - Língua(gem) e Ensino, Programa de Pós-Graduação em Ciências da Linguagem (PPGCL), Universidade do Vale do Sapucaí (UNIVÁS), Pouso Alegre (MG), vol. 14, p. 243-260, jan. - jun. 2017.

DOI: http://dx.doi.org/10.20337/ISSN2179-3514revistaENTREMEIOSvo114pagina243a260 